\title{
Polymer waste as a combustible additive for wall ceramics production
}

\author{
Kseniya Perovskaya ${ }^{1}$, Daria Petrina ${ }^{1}$, Evgeniy Pikalov ${ }^{1, *}$, and Oleg Selivanov ${ }^{1}$ \\ ${ }^{1}$ Vladimir State University named after A.G. and N.G. Stoletovs, 600000 Vladimir, Russia
}

\begin{abstract}
The research presents the experimental results devoted to the charge composition development for the production of wall ceramic products, based on low plasticity clay using additives. One of the additives is polymer waste in the amount of $15 \mathrm{wt} . \%$, in particular it is unplasticized polyvinyl chloride used as a combustible additive for increasing ceramics porosity thus decreasing its density and consequently the load on the basement when the walls are constructed. Besides it decreases thermal conductivity and improves energy efficiency of developed wall ceramics application. Boric acid is a second additive used as a fuse thus reducing the temperature of ceramics liquid-phase sintering and forming a vitreous phase, which increases the strength characteristics and reduces water absorption, and therefore increases the product frost resistance. However the vitreous phase amount is insignificant and the products still are characterized by porosity sufficient for density and thermal conductivity reduction up to the level of conditionally effective thermal performance. Thus the application of the developed wall ceramics facilitate the production of energy effective products, which can be used for multi-layers walls construction providing modern thermal engineering standards and rational consumption of building materials. Herewith the developed materials properties correspond to the requirements of solid ceramic bricks used in Russian climatic conditions and help to combine the functions of bearing, heat-insulating and partly facing layers to a certain extend thus expanding their application.
\end{abstract}

\section{Introduction}

Modern construction basically applies concrete and ceramic products for the walls, the latter are of great demand due to their variety, design, strength and frost resistance. Thanks to these advantages wall ceramic products are among the most ancient construction materials and they still remain relevant today. The most common wall ceramic products are small-pieces, which include various types of bricks and stone.

Throughout the entire period of wall ceramics application, their basic production principles have not considerably changed -they are still manufactured basing on raw clay by mixing it with water, forming under pressure and subsequent heat treatment: drying and firing before sintering [1]. Depending on the raw materials properties and operational

\footnotetext{
* Corresponding author: evgeniy-pikalov@mail.ru
} 
requirements, the production technological parameters and ceramic charge composition are changed. Functional additives are additionally introduced into the charge, changing the products structure and properties like technological parameters, thus improving the product quality.

Lately energy saving has been paid special attention during buildings construction. It is connected with the price increase heat thermal engineering standards. Therefore, the application of traditional ceramic products is getting difficult since it is required to make brickwork thicker to meet the modern standards, thus increasing construction cost and reducing inner free space. To comply with thermal engineering standards and ensure the construction materials rational consumption the multi-layer walls construction is applied including energy-efficient products.

The most common option is a three-layer wall construction, where the inner layer is made of solid ceramic brick for load-bearing, the middle layer is made of thermal insulation material for providing thermal requirements, and the outer layer is made of facing brick or other products. Bearing layers made of energy-efficient ceramic bricks is important for construction, as it allows further reduction the brickwork thickness in compliance with thermal standards [2].

Ceramic products energy efficiency implies their low thermal conductivity, which keeps the heat inside the buildings. The easiest way to reduce the products thermal conductivity is to increase their porosity, which can be easily provided by using of combustible additives.

The current research considers the possibility to improve the energy efficiency of wall ceramic products, manufactured on the basis of low-plasticity clay through introducing polymer waste as a burning additive.

As the production application low-plastic clays is limited due to low strength, frost resistance and crack resistance of the products manufactured on their basis, a fuse is introduced into the charge alongside with the burning additive to reduce the sintering temperature of the material, increase its strength and reduce water absorption.

Polymer waste as a combustible additive is substantiated by its large-capacity, resistant to decomposition and is characterized by poor density, and therefore large accumulation volume. In addition, polymer waste consumption is characterized by the instability and lower physical and mechanical properties compared to the primary polymer raw materials due to its partial destruction and the possible presence of non-polymer inclusions and impurities of other polymers thus complicating its recovery [3-5].

The authors have previously developed charge compositions on the basis of lowplasticity clay for wall [6] and facing materials [7-10]. The mentioned compositions included two groups of additives to increase ceramics strength and reduce water absorption: additives which are the vitreous phase source, and additives reducing the temperature of liquid-phase sintering and increasing the vitreous phase amount.

In this research, it has been decided to introduce only a fuse to reduce the temperature of liquid-phase sintering, since the formation of a large number of vitreous phase significantly reduces porosity leading to the decrease product energy efficiency.

\section{Materials and Methods}

The basic charge component, used for developing wall ceramics, was low-plasticity clay from Suvorotskoye field of the Vladimir region of the following composition (wt.\%): $\mathrm{SiO}_{2}$ $=67,5 ; \mathrm{Al}_{2} \mathrm{O}_{3}=10,75 ; \mathrm{Fe}_{2} \mathrm{O}_{3}=5,85 ; \mathrm{CaO}=2,8 ; \mathrm{MgO}=1,7 ; \mathrm{K}_{2} \mathrm{O}=2,4 ; \mathrm{Na}_{2} \mathrm{O}=0,7$. The reasons for the clay low plasticity are the presence of sufficiently big amount of aluminum, calcium and magnesium. The clay plasticity index, determined by the standard method, was 5.2, and, consequently, in compliance with GOST 9169-75, it belongs to the low-plasticity type [10]. 
Waste from unplasticized polyvinyl chloride (UPVC) - the waste from building profiles and finishing panels consumption in particular - was used as a burning additive in the developed composition of the charge. On the one hand, this waste is associated with large production and consumption volumes of profiles and panels, which causes large amount of waste. On the other hand, UPVC is not a thermally stable polymer so it additionally complicates its recycling, thus its application as a combustible additive can become an alternative disposal option. It should be noted that UPVC combustion emits toxic gases, including hydrochloric acid vapor, so it is necessary to process UPVC combustion products additionally by reburning them at the temperature of $1200-1400{ }^{\circ} \mathrm{C}$, when toxic compounds decompose, to clean the flue gases using sorption methods of cleaning or dry cleaning, i.e. to introduce quicklime, magnesium oxide or sodium hydroxide into the dust gases, which interact with toxic combustion products and form harmless compounds. For example, the lime neutralizes the hydrogen chloride with the formation of calcium chloride [3].

In the research, boric acid B grade 2 (GOST 18704-78) with a basic material mass fraction of $98,6 \%$ was used as a fuse. Its efficiency was proved in the previous experiments [6-10], their result found that this additive can increase the strength and reduce the water absorption of ceramics based on the low-plasticity clay.

Semi-dry pressing technology was used to obtain samples of the developed ceramics [6]. Clay and polymer waste were pre-dried reaching the constant mass and crushed with further selection of max $0.63 \mathrm{~mm}$ fraction. Afterwards the charge components were weighed in the required ratio and mixed first in a dry state, and then with water to obtain a molding mass with a moisture content of 8 wt. \%. The samples were made from the resulting molding mass at a specific pressing pressure of $15 \mathrm{MPa}$ and a maximum firing temperature of $1050^{\circ} \mathrm{C}$. Due to low humidity of the molding mass, the samples were not dried. Samples were made in batches of three samples each.

For the samples performance and energy efficiency assessment of the developed wall ceramics the following characteristics have been determined according to the standard methods for ceramic materials: compression strength $\left(\sigma_{\mathrm{cs}}, \mathrm{MPa}\right)$, bending strength $\left(\sigma_{\mathrm{bs}}\right.$, $\mathrm{MPa})$, water absorption $(\mathrm{W}, \%)$, frost resistance $\left(\mathrm{F}\right.$, cycles), density $\left(\rho, \mathrm{kg} / \mathrm{m}^{3}\right)$, thermal conductivity $\left(\lambda, \mathrm{Wt} /\left(\mathrm{m}^{2} \cdot{ }^{\circ} \mathrm{C}\right)\right)$, open $\left(\mathrm{P}_{\mathrm{opn}}, \%\right)$ and total $\left(\mathrm{P}_{\text {tot }}, \%\right)$ porosity.

\section{Results}

The first experimental stage was devoted to the separate impact of polymer waste and boric acid on compression strength and water absorption of ceramics on the basis of the low plasticity clay.

When boric acid is introduced as an additive in the amount of up to $3 \mathrm{wt}$ \% (see Fig. 1, a), a significant increase of compressive strength and water absorption decrease is observed. Further increase of boric acid amount does not greatly affect the properties of the resulting ceramics. The dependence character is explained by the fact that boric acid forms a vitreous phase during firing, which serves as a binder between the ceramic particles, thus hardening the material, but the amount of the vitreous phase is not enough to reduce water absorption significantly, and therefore the material porosity is sufficient to increase the products energy efficiency.

As the data concerning the polymer waste introduction into the charge shows (see Fig. $1, \mathrm{~b}$ ) alongside the additive amount increase significant compressive strength reduction and the significant material water absorption increase occurs.

This is due to the fact, that quite a lot of pores and voids are formed during the polymer waste combustion at firing within the material volume. Moreover basing on these data the following conclusion can be made a separate introduction of polymer waste as a 
combustion additive does not allow to obtain ceramics possessing sufficiently high compressive strength and low water absorption, thus leading to frost resistance decrease.

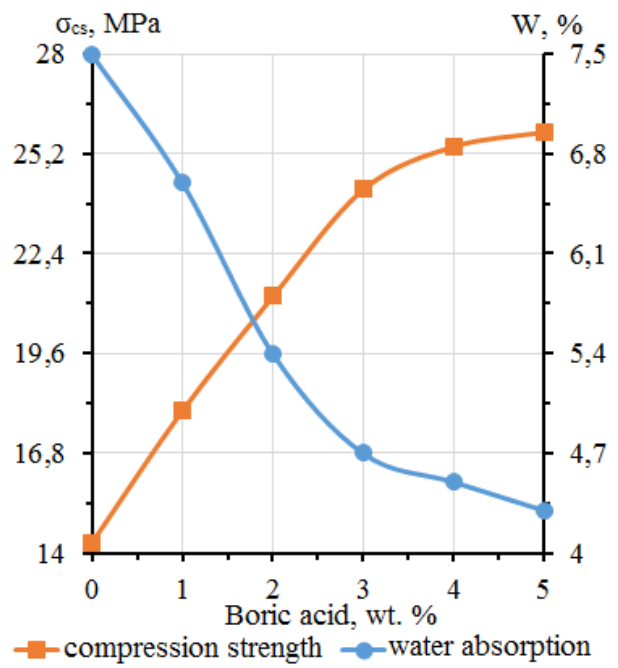

a)

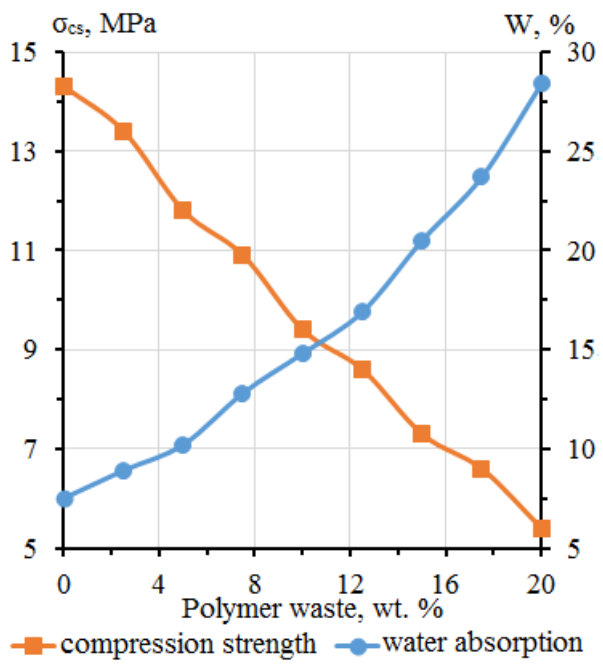

b)

Fig. 1. Dependence of compression strength and water absorption on boric acid (a) and polymer waste (b) amount.

It should be noted that according to the previous experiments results it was determined that without the vitreous phase forming additives, the boric acid amount in the charge should be limited to $2,5 \mathrm{wt}$. \% since higher additive concentrations decrease environmental safety of ceramics as boric acid belongs to the $3 \mathrm{rd}$ hazard class $[6,9]$.

In respect to the obtained data and the results of previously developed charge compositions, the second stage of the research was devoted to the effect of the polymer waste amount on the wall ceramics basic properties at the introduction of $2,5 \mathrm{wt} . \%$ boric acid into the charge.

Fig. 2 data demonstrate that similar relation occurs during the joint introduction of cullet and boric acid i.e. it leads to the decrease of compressive and bending strength. However, unlike separate introduction of polymer waste (see Fig. 1, b) the strength decrease is not so significant so it proves the effectiveness of the boric acid introduction in addition to polymer waste.

Figure 2 also shows that the additional introduction of boric acid reduces water absorption as compared to ceramics obtained only using polymer waste additives, and consequently allows to achieve sufficiently high frost resistance of the produced wall ceramics.

Basing on Fig. 3 it can be concluded that the joint introduction of polymer waste and boric acid density and thermal conductivity of the developed wall ceramics are reduced alongside the increase polymer waste amount in the charge, thus leading to the increase of products energy efficiency and reduction the load on the foundation during the walls construction.

The decrease of density and thermal conductivity occurs because of the open and total porosity increase of the developed material as a result of polymer waste burnup during firing. 


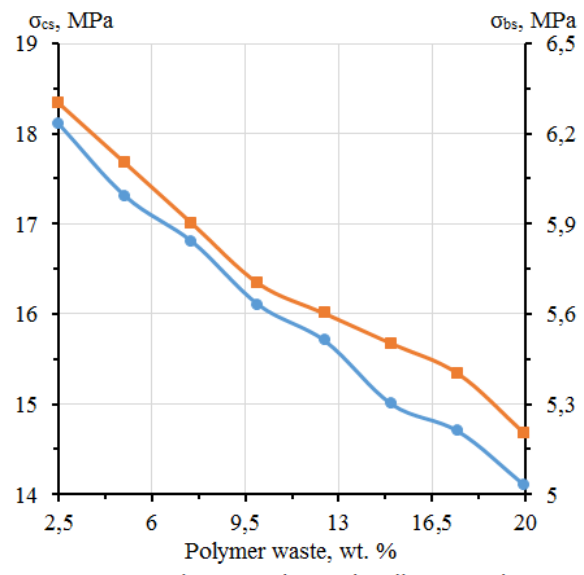

$\rightarrow$ compression strength - - bending strength

a)

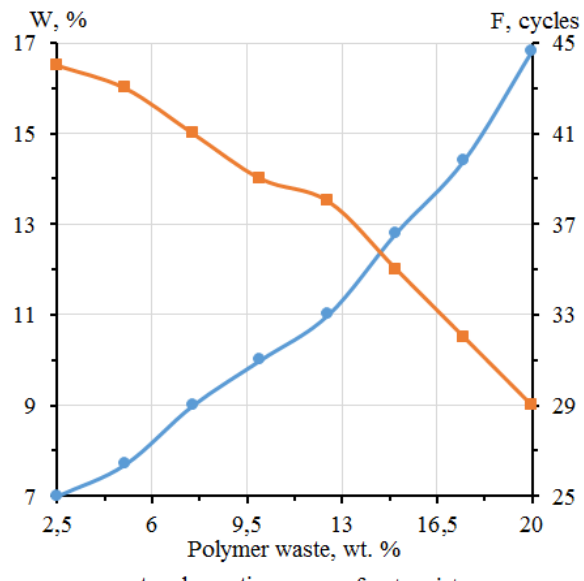

b)

Fig. 2. Dependence of compressive and bending strength (a), water absorption and frost resistance (b) on polymer waste amount when $2,5 \mathrm{wt}$. \% boric acid is introduced.

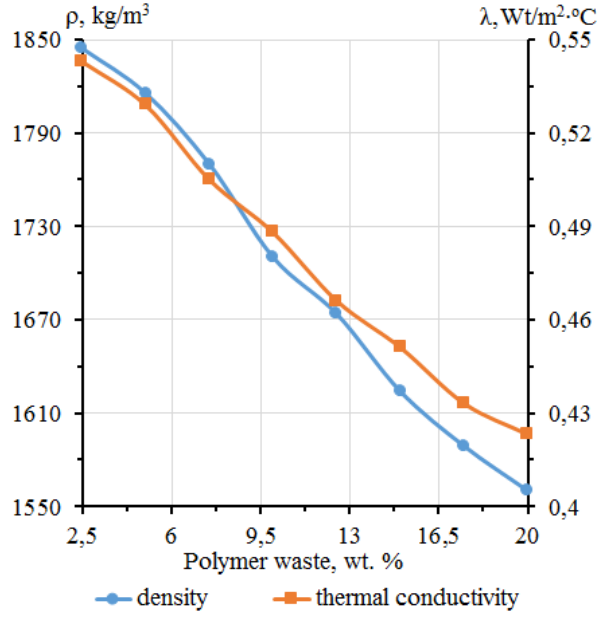

a)

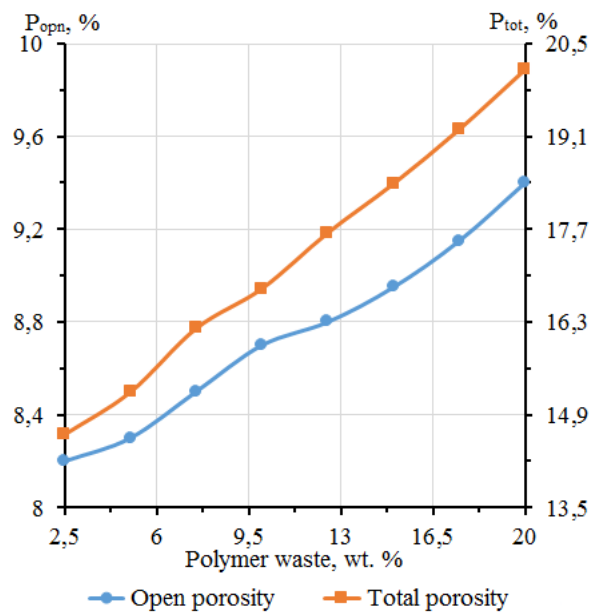

b)

Fig. 3. Density and thermal conductivity dependence (a), open and total porosity (b) on polymer waste amount and $2,5 \mathrm{wt}$. \% of boric acid introduction.

Summarizing the data from Fig. 2 and 3, considering that compressive strength is of great importance for wall products, it has been decided to limit the polymer waste amount to $15 \mathrm{wt}$. \%. The given quantity of polymer waste facilitates reaching the specified property of $15 \mathrm{MPa}$, thus meeting the requirements of GOST 530-2012 for the average corpulent ceramic brick brand M150, used in buildings construction suitable for Russia climatic conditions. The main properties of the developed wall ceramics, obtained on the basis of the charge at a given content of polymer waste, in comparison with the requirements of this GOST and the properties of ceramics based on the studied low-plastic clay without the introduction of additives are shown in the table.

The basic properties of the developed wall ceramics produced on the basis of the charge at a given polymer waste amount, in comparison with the requirements of the specified GOST and the ceramics based on the researched low-plasticity clay without the 
introduction of any additives are shown in the table. In the case of GOST 530-2012 requirements the table shows the data on strength and thermal conductivity for energyefficient solid brick brand M150.

Table 1. Acid resistant ceramics properties.

\begin{tabular}{|c|c|c|c|c|c|c|c|c|}
\hline Composition & $\begin{array}{c}\sigma_{\mathrm{cs}}, \\
\mathrm{MPa}\end{array}$ & $\begin{array}{c}\sigma_{\mathrm{bs}} \\
\mathrm{MPa}\end{array}$ & $\begin{array}{c}\mathrm{W}, \\
\%\end{array}$ & $\begin{array}{c}\mathrm{F}, \\
\text { cycles }\end{array}$ & $\begin{array}{c}\rho, \\
\mathrm{kg} / \mathrm{m}^{3}\end{array}$ & $\begin{array}{c}\lambda, \\
\mathrm{Wt} /\left(\mathrm{m}^{2.0} \mathrm{C}\right)\end{array}$ & $\begin{array}{c}\mathrm{P}_{\text {opn, }} \\
\%\end{array}$ & $\begin{array}{c}\mathrm{P}_{\text {tot, }} \\
\%\end{array}$ \\
\hline GOST 530-2012 & 15.0 & 2.8 & $>5$ & $>25$ & - & $<0.46$ & - & - \\
\hline No additives & 14.3 & 7.4 & 7.5 & 41 & 1936.4 & 0.562 & 8.0 & 13.8 \\
\hline Developed & 15.0 & 5.5 & 12.8 & 35 & 1623.8 & 0.451 & 8.95 & 18.38 \\
\hline
\end{tabular}

Thus, the developed charge composition improves the products quality based on lowplasticity clay and their properties meet the requirements of GOST 530-2012 for energyefficient solid ceramic bricks for the buildings construction in the climatic conditions of Russia.

\section{Conclusions}

The research resulted in the development of the charge composition on the basis of lowplasticity clay, including $15 \mathrm{wt} . \%$ of polymer waste as a combustion additive and 2,5 wt.\% of boric acid. This composition allows to receive high quality wall ceramic products for suitable for the climatic conditions of Russia. This charge composition application promotes the usage of low-plasticity clay, which is not widely used because of poor quality products produced from it, and utilization of polymer waste which processing is complicated due to low physical and mechanical properties, as well as low thermal stability in the case of the proposed in the developed composition of UPVC.

The properties of the developed wall ceramics meet the requirements of GOST 530-2012 concerning the application of ceramic brick and stone for the construction of buildings and structures. The material frost resistance not only meets the requirements of the specified GOST, but also allows the usage of the developed wall ceramics for the facial ceramic bricks production, for which the minimum frost resistance requirement equals to 35 cycles.

Thermal conductivity of the developed wall ceramics corresponds to the products conditionally effective thermal characteristics, for which the thermal conductivity ranges from 0.36 to $0.46 \mathrm{Wt} /\left(\mathrm{m}^{2} \cdot{ }^{\circ} \mathrm{C}\right)$. Other properties of the developed wall ceramics are average for the ceramic bricks.

Thus, the use of the developed wall ceramics promotes the production of energyefficient products which can be used in the multi-layer walls construction, providing modern thermal standards and rational consumption of building materials. Herewith the developed material properties allow to a certain extent to combine the functions of the bearing, thermal insulation and partly facing layers thus expanding their possible application.

\section{References}

1. I.I. Moroz, Construction ceramics technology (ECOLIT, Moscow, 2011)

2. G.M. Badyin, S.A. Sychev, Modern technologies of building construction and reconstruction (BHV-Petersburg, SPb 2013)

3. V.N. Shakhova, A.A. Vorobyev, I.A. Vitkalova, A.S. Torlova, E.S. Pikalov, Modern high technologies 11-2, 320-325 (2016) 
4. M.V. Bazinova, Y.A. Prochukhan, Bulletin of Bashkir University 13(4), 875-885 (2008)

5. V.V. Snezhkov, G.V. Retsits, Solid waste 1, 16-19 (2011)

6. E.S. Pikalov, O.G. Selivanov, V.Y. Chukhlanov, N.V. Chukhlanova, Ecology and industry in Russia 6, 24-29 (2017)

7. A.A. Vorob'eva, V.N. Shakhova, E.S. Pikalov, O.G. Selivanov, É.P Sysoev, V.Y. Chukhlanov, Glass and Ceramics 75 (1-2), 51-54 (2018)

8. V. Shakhova, I. Vitkalova, A. Torlova, E. Pikalov, O. Selivanov, MATEC Web of Conferences 193, 03032 (2018) doi.org/10.1051/matecconf/201819303032

9. I. Vitkalova, A. Torlova, E. Pikalov, O.Selivanov, MATEC Web of Conferences 193, 03035 (2018) doi.org /10.1051/matecconf/201819303035

10. I. Vitkalova, A. Torlova, E. Pikalov, O. Selivanov, E3S Web of Conferences 33, 02062 (2018) doi.org/10.1051/e3sconf/20183302062 